\title{
CORRECTION
}

\section{Correction to: Imaging tools for assessment of myocardial fibrosis in humans: the need for greater detail}

\author{
Summer Hassan ${ }^{1,2} \cdot$ Carolyn J Barrett $^{1} \cdot$ David J Crossman $^{1}$ (D)
}

Published online: 19 November 2021

○ International Union for Pure and Applied Biophysics (IUPAB) and Springer-Verlag GmbH Germany, part of Springer Nature 2021

\section{Correction to: Biophysical Reviews (2020) 12:969-987}

https://doi.org/10.1007/s12551-020-00738-w

Table 1 of the original article was published with an error in the "Confocal microscope".

Incorrect data: $5-50 \mathrm{~nm}$

Correct data: $250 \mathrm{~nm}$

The corrected Table 1 is shown below.

Table 1 The resolutions achieved by different imaging modalities of the myocardium (Eugene Lin, 2009)

\begin{tabular}{ll}
\hline Imaging modality & $\begin{array}{l}\text { Spatial resolution full width } \\
\text { at half maximum (FWHM) }\end{array}$ \\
\hline Echocardiography & $\sim 0.5-2 \mathrm{~mm}$ \\
CT & $0.5-0.625 \mathrm{~mm}$ \\
MRI & $1-2 \mathrm{~mm}$ \\
PET & $4-10 \mathrm{~mm}$ \\
SPECT & $4-15 \mathrm{~mm}$ \\
Electron microscope & $1-10 \mathrm{~nm}$ \\
Confocal microscope & $250 \mathrm{~nm}$ \\
\hline
\end{tabular}

The original article has been corrected.

Publisher's note Springer Nature remains neutral with regard to jurisdictional claims in published maps and institutional affiliations.

The original article can be found online at https://doi.org/10.1007/ s12551-020-00738-w.

David J Crossman

d.crossman@auckland.ac.nz

1 Department of Physiology, University of Auckland, Auckland, New Zealand

2 Auckland City Hospital, Auckland District Health Board, Auckland, New Zealand 